\title{
Superior Sinus Venosus Atrial Septal Defect: Overview of Surgical Options*
}

\author{
Kelechi Emmanuel Okonta $^{1 \#}$, Michael Sanusi ${ }^{2}$ \\ ${ }^{1}$ Cardiothoracic Surgery Unit, Department of Surgery, University of Port Harcourt, Rivers State, Nigeria; ${ }^{2}$ Cardiothoracic Surgery \\ Unit, Department of Surgery, Lagos State University Teaching Hospital, Ikeja, Lagos State, Nigeria. \\ Email: "okontakelechi@yahoo.com
}

Received August $26^{\text {th }}, 2013$; revised September $26^{\text {th }}, 2013$; accepted October $3^{\text {rd }}, 2013$

Copyright (C) 2013 Kelechi Emmanuel Okonta, Michael Sanusi. This is an open access article distributed under the Creative Commons Attribution License, which permits unrestricted use, distribution, and reproduction in any medium, provided the original work is properly cited. In accordance of the Creative Commons Attribution License all Copyrights (C) 2013 are reserved for SCIRP and the owner of the intellectual property Kelechi Emmanuel Okonta, Michael Sanusi. All Copyright (C) 2013 are guarded by law and by SCIRP as a guardian.

\begin{abstract}
Background: Superior sinus venosus atrial septal defect (SV-ASD) is an interatrial defect with partial anomalous pulmonary venous connection (PAPVC) draining into the right atrium. The principle for SV-ASD surgical repair involves redirecting the pulmonary venous blood back to the left atrium and closure of the atrial septal defect without compromising the adjoining structures. Methods: We reviewed English literature relating to this topic via a MEDLINE and Google scholar search using the following terms: surgery for sinus venosus atrial septal defect (SV-ASD), surgery for partial anomalous pulmonary venous connection (PAPVC) and complications of the surgery. Results: A total of 910 consecutive cohort patients with different surgical options between 1984 to 2012 were analyzed. The breakdown showed that 291(32.0\%) had single-patch, 275(30.2\%) had Warden's procedure, 185(20.3\%) had a double-patch and $159(17.5 \%)$ had use of autologous right atrial appendage for the anastomosis. The total follow-up was between 0.008 30 years. Sinus node dysfunction (SND) was the commonest complication occurring mostly in patients who had doublepatch technique $16(8.6 \%)$ followed by $15(5.5 \%)$ patients with single-patch technique, $7(4.4 \%)$ patients in whom right atrial appendage was used and 5(1.8\%) patients with Warden's procedure. Venous obstruction occurred in 22(7.7\%) patients with SP, 13(5.1\%) patients with Warden's Procedure and 5(2.7\%) patients with double-patch. Conclusion: The two major complications, SND and venous obstruction, assumed a see-saw approach as surgical maneuvers avoiding venous obstruction encouraged SND and vice versa. However, adopting surgical options which avoided incision across the Cavoatrial junction attenuated all the complications.
\end{abstract}

Keywords: Sinus Venosus-Atrial Septal Defect; Warden's Procedure; Right Atrial Appendage; Single-Patch Technique; Double-Patch Technique

\section{Introduction}

Superior sinus venosus atrial septal defect (SV-ASD) is a form of interatrial defect which in most cases is associated with partial anomalous pulmonary venous connection (PAPVC) with the right pulmonary vein draining into the right atrium from the superior vena cava (SVC), at the cavoatrial junction or directly into the right atrium [1]. Its morphogenesis is still not clear; however, the consensus was that the Common Pulmonary Vein devel-

\footnotetext{
*Acknowledge: None.

No source of funds.

${ }^{\#}$ Corresponding author.
}

ops within the primitive sinus venosus segment and that later a common myocardial wall is present between the sinus venosus in the right atrium and the Common Pulmonary Vein, thus a deficiency of this wall explains the development of sinus venosus defects [2].

The principle for SV-ASD surgical repair involves redirecting the pulmonary venous blood back to the left atrium and closure of the atrial septal defect without compromising the adjoining structures. This has led to the evolution of different surgical options [3,7-9].

The aim of this systematic review is to give an overview of the different surgical options with a suggestion on the best surgical options to be adopted. 


\section{Method}

We identified and reviewed the English literature relating to this topic via a MEDLINE and Google scholar search using the following terms: surgery for sinus venosus atrial septal defect (SV-ASD), surgery for partial anomalous pulmonary venous connection (PAPVC) and complications of the surgery. The search was restricted to English language literatures with no limitations to years of study. The relevant studies which listed the surgical options, either single or in combination with other methods were analyzed, and surgical options such as Warden's procedure, single-patch technique, double Patch technique, autologous right atrial appendage and reimplantation of pulmonary vein with their associated complications and important outcomes were given priority. The abstracts were again carefully reviewed independently by the authors giving consideration to the strength of the study vis a vie clarity with respect to the background, the methodology, the results and the conclusion. The studies with more than one surgical option were carefully sorted out using the number of patients for whom a particular surgery was applied to and entered into the respective groups. The search was subsequently repeated to avoid missing out any relevant article. Expert opinions were sought in preparing the outline for the review, the criteria for the classification of surgical options and related complications.

\section{Surgical Techniques}

The principle of Warden's procedure involved the transecting of the SVC above the orifices of PAPVC and over sewing the distal stump above the anomalous pulmonary vein. The tip of the right atrial appendage was amputated and then anastomosis to the proximal SVC using absorbable sutures to take care of future growth (especially in children). A synthetic patch or autologous pericardium is used to suture the margin of the sinus venosus defect, baffling the SVC orifice to direct blood flow into the left atrium. An SVC to right atrial gradient greater than $4 \mathrm{mmHg}$ is unacceptable. [10].

In the reimplantation technique, a modified tube graft and internal patch technique is used to redirect the anomalous pulmonary venous return through the sinus venosus defect by baffling the structures with a pericardial autologous pericardial flap and ASD dilatation for the pulmonary venous drainage channel [11].

In the use of autogenous right atrial appendage in rechanneling SV-ASD with PAPVC; the cavo-atrial anastomosis is established using the tip of the right atrial appendage thus creating a double outlet for SVC flow and preserving the cavo-atrial junction [12].

Single-patch involves the use of the pericardial path to baffle the right upper pulmonary vein via the ASD into the left atrium. The incision to placing the baffle could be via the cavotomy (anterior or lateral), right atriotomy or incision incorporating the caval and atrium across the cavoatrial junction.

The double patch could involve any of the above stated incisions, however augumentation patch is used to enlarge the cavotomy or cavoatriotomy

\section{Result}

The search generated 201 articles which were subsequently searched at face value scaling it down to 56 articles. The surgical options were grouped into 5 types; 1 ) Single-patch technique [13-20] Table 1, 2) Double-patch technique [13,16,17,19,21-23] Tables 2, 3) Warden's procedure [16,19,24-34] Table 3, 4) Autologous right atrial appendage [14,35-40] and 5) reimplantation of pulmonary vein [41-43] Table 4 . These results were subsequently analyzed using another table (Table 5). The complications were grouped into 4 namely: 1) Sinus node dysfunction (SND), 2) systemic venous obstruction, 3) pulmonary venous obstruction and 4) Others.

Three studies which compared either 2 or 3 surgical options were found $[16,17,19]$ for which two with the same surgical options were used for tabulation $[13,16]$ (Table 5). Two meta-analyses was found [41,42].

The studies with no figures/numbers or with lumped up results were also excluded from the computation of results $[20,39,43-49]$.

The single-patch technique was adopted in 8 studies with a total of 291 consecutive patients (1986-2012). Fifteen patients $(5.5 \%)$ had sinus node dysfunction, 12 (4.4\%) had systemic venous obstruction, 10(3.6\%) had pulmonary venous obstruction with a follow up periods ranging between 0.3 - 24 years (Table 1).

The double-patch technique was similarly adopted in 8 studies with a total of 185 consecutive patients (19932012). Sixteen patients $(8.6 \%)$ had sinus node dysfunction, $4(2.2 \%)$ systemic venous obstruction, $1(0.5 \%)$ pulmonary venous obstruction and $1(0.5 \%)$ had heart failure. The follow up period was 1.9 - 16 years (Table 2).

The Warden's procedure was adopted in 12 studies with a total of 275 consecutive patients (1984-2012).Five patients $(1.8 \%)$ had sinus node dysfunction, $8(2.9 \%)$ had systemic venous obstruction, $5(1.8 \%)$ had pulmonary venous obstruction and $1(0.4 \%)$ other complication of pulmonary hypertension with a follow up period of 0.08 30 yr (Table 3).

The was autologous right atrial appendage adopted in 7 studies with a total of 159 consecutive patients (19932011). Seven patients $(4.4 \%)$ had sinus node dysfunction, no patient had sinus venous obstruction or pulmonary venous obstruction. One $(0.6 \%)$ had complete heart block with a follow up of $0.08-8.6$ years (Table 4).

The relevant studies for reimplantation of the right 
Table 1. The articles with single-patch technique.

\begin{tabular}{|c|c|c|c|c|c|c|c|}
\hline NO & $\begin{array}{c}\text { Author } \\
\text { Country } \\
\text { Year }\end{array}$ & $\begin{array}{l}\text { Number } \\
\text { Patients }\end{array}$ & SND & SVO & PVO & $\begin{array}{c}\text { Other } \\
\text { Complications }\end{array}$ & $\begin{array}{l}\text { Follow } \\
\text { up }\end{array}$ \\
\hline 1 & $\begin{array}{c}\text { Stewart }^{[13]} \\
\text { USA } \\
1986\end{array}$ & 15 & 6 & - & - & - & - \\
\hline 2 & $\begin{array}{c}\text { Deleon }^{[14]} \\
\text { USA } \\
1988\end{array}$ & 17 & - & 1 & - & - & - \\
\hline 3 & $\begin{array}{l}\text { Nicholson }^{[15]} \\
\text { Australia } \\
2000\end{array}$ & 66 & - & - & - & - & $\begin{array}{l}1-9 \mathrm{YR} \\
\mathrm{S}\end{array}$ \\
\hline 4 & $\begin{array}{l}\text { Stewart }^{[16]} \\
\text { USA } \\
2007\end{array}$ & 24 & 5 & 2 & - & - & - \\
\hline 5 & $\begin{array}{c}\text { Iyer }^{[17]} \\
\text { India } \\
2007\end{array}$ & 18 & 4 & 6 & 9 & - & 1.9 \\
\hline 6 & $\begin{array}{l}\text { Gajjar }^{[18]} \\
\text { India } \\
2011\end{array}$ & 48 & - & - & - & - & $0.3-2$ \\
\hline 7 & $\begin{array}{c}\text { Said }^{[19]} \\
\text { USA } \\
2012\end{array}$ & 60 & - & 3 & 1 & - & - \\
\hline \multirow[t]{2}{*}{8} & $\begin{array}{l}\text { Nassar }^{[20]} \\
\text { France } \\
2012\end{array}$ & 43 & - & - & - & - & - \\
\hline & & 291 & $\begin{array}{c}15 \\
(5.2 \%)\end{array}$ & $\begin{array}{c}12 \\
(4.1 \%)\end{array}$ & $\begin{array}{c}10 \\
(3.8 \%)\end{array}$ & 0 & $0.3-24$ \\
\hline
\end{tabular}

Table 2. The article with double-patch technique.

\begin{tabular}{|c|c|c|c|c|c|c|c|}
\hline NO & $\begin{array}{l}\text { Author } \\
\text { Country } \\
\text { Year }\end{array}$ & $\begin{array}{l}\text { Number } \\
\text { Patient }\end{array}$ & SND & SVO & PVO & $\begin{array}{c}\text { Other } \\
\text { Complication }\end{array}$ & $\begin{array}{l}\text { Follow } \\
\text { up (yr) }\end{array}$ \\
\hline 1 & $\begin{array}{c}\text { Deleon }^{[14]} \\
\text { USA } \\
1993\end{array}$ & 18 & 2 & - & - & - & - \\
\hline 2 & $\begin{array}{c}\text { Victor }^{[21]} \\
\text { India } \\
1995\end{array}$ & 30 & - & - & - & - & - \\
\hline 3 & $\begin{array}{c}\text { Agrawal }^{[22]} \\
\text { India } \\
1997\end{array}$ & 44 & 2 & - & - & - & $3.3-4.7$ \\
\hline 4 & $\begin{array}{c}\text { Jemielity }^{[23]} \\
\text { Poland } \\
1998\end{array}$ & 25 & - & 1 & - & $\begin{array}{l}1 \text { Heart } \\
\text { Failure }\end{array}$ & $2-16$ \\
\hline 5 & $\begin{array}{l}\text { Iyer }^{[17]} \\
\text { India } \\
2007\end{array}$ & 19 & - & 2 & - & - & 1.9 \\
\hline 6 & $\begin{array}{c}\text { Stewart }^{[16]} \\
\text { USA } \\
2007\end{array}$ & 25 & 12 & - & - & - & - \\
\hline 7 & $\begin{array}{l}\text { Said }^{[33]} \\
\text { USA } \\
2012\end{array}$ & 24 & - & 1 & 1 & - & - \\
\hline & & 185 & $\begin{array}{c}16 \\
(8.6 \%)\end{array}$ & $\begin{array}{c}4 \\
(2.2 \%)\end{array}$ & $\begin{array}{c}1 \\
(0.5 \%)\end{array}$ & $1(0.5 \%)$ & $1.9-16$ \\
\hline
\end{tabular}

Table 3. The article with Warden's procedure.

\begin{tabular}{|c|c|c|c|c|c|c|c|}
\hline NO & $\begin{array}{l}\text { Author } \\
\text { Country } \\
\text { Year }\end{array}$ & $\begin{array}{c}\text { Number } \\
\text { Patient }\end{array}$ & SND & SVO & PVO & Other & $\begin{array}{l}\text { Follow } \\
\text { up (yr) }\end{array}$ \\
\hline 1 & $\begin{array}{c}{ }^{*} \text { Warden }^{[24]} \\
\text { USA } \\
1984\end{array}$ & 15 & - & 1 & - & $\begin{array}{l}1 \text { Pulmonary } \\
\text { Hypertension }\end{array}$ & - \\
\hline 2 & $\begin{array}{c}\text { Gustafson }^{[25]} \\
\text { USA } \\
1985\end{array}$ & 27 & & & & & \\
\hline 3 & $\begin{array}{c}\text { Gustafson }^{[26]} \\
\text { USA } \\
1995\end{array}$ & 40 & 1 & - & - & - & $0.5-30$ \\
\hline 4 & $\begin{array}{c}\text { Gaynor }^{[27]} \\
\text { England } \\
1995\end{array}$ & 11 & - & - & 1 & - & $2.3+/-1.4$ \\
\hline 5 & $\begin{array}{c}\text { Dibardino }^{[28]} \\
\text { USA } \\
2004\end{array}$ & 16 & 1 & - & - & - & 5.6 \\
\hline 6 & $\begin{array}{l}\text { Nakahira }^{[29]} \\
\text { Japan } \\
2006\end{array}$ & 20 & - & 2 & - & - & 6.5 \\
\hline 7 & $\begin{array}{c}\text { Shahriari }{ }^{[30]} \\
\text { USA } \\
2006\end{array}$ & 13 & - & - & $1 \mathrm{~L}$ & - & $1-13$ \\
\hline 8 & $\begin{array}{c}\text { Stewart }^{[16]} \\
\text { USA } \\
2007\end{array}$ & 5 & - & 1 & - & - & - \\
\hline 9 & $\begin{array}{l}{ }^{*} \text { Said }^{[19]} \\
\text { USA } \\
2011\end{array}$ & 8 & 1 & 1 & - & - & $2+/-2.6$ \\
\hline 10 & $\begin{array}{c}\text { Park }^{[31]} \\
\text { Korea } \\
2011\end{array}$ & 30 & 1 & 3 & 1 & - & $0.08-16$ \\
\hline 11 & $\begin{array}{c}\text { Agarwal }^{[10]} \\
\text { India } \\
2011\end{array}$ & 58 & - & - & - & - & $1-2.8$ \\
\hline 12 & $\begin{array}{l}\text { Kottayil }^{[32]} \\
\text { India } \\
2011\end{array}$ & 32 & 1 & - & - & - & 2 \\
\hline 13 & $\begin{array}{c}\text { Said }^{[33]} \\
\text { USA } \\
2012\end{array}$ & 40 & 1 & 3 & - & - & - \\
\hline & & 316 & $\begin{array}{c}6 \\
(1.9 \%)\end{array}$ & $\begin{array}{c}11 \\
(3.5 \%)\end{array}$ & $\begin{array}{c}5 \\
(1.6 \%)\end{array}$ & & $0.08-30$ \\
\hline
\end{tabular}

upper pulmonary vein into the right atrium and subsequently baffling into the left atrium [11,39] or reimplantation directly into the left atrium[40].

The summary from all the studies showed that a total of 910 patients had the different surgical options between 1984 and 2012. The breakdown showed that 291(32.0\%) had single-patch technique, 275(30.2\%) had Warden's procedure, $185(20.3 \%)$ had double-patch technique and $159(17.5 \%)$ had with autologous right atrial appendage a total follow up ranging between 0.008 - 30 years.

Sinus node dysfunction was the commonest complication occurring mostly in patients who had double-patch technique $16(8.6 \%)$ followed by $15(5.5 \%)$ in those who had single-patch technique, $7(4.4 \%)$ in those who had 
Table 4. The articles with autogenous/autologous right atrial appendage technique.

\begin{tabular}{|c|c|c|c|c|c|c|c|}
\hline NO & $\begin{array}{c}\text { Author } \\
\text { Country } \\
\text { Year }\end{array}$ & $\begin{array}{c}\text { Number } \\
\text { Patient }\end{array}$ & SND & SVO & PVO & Other & $\begin{array}{l}\text { Follow } \\
\text { up (yr) }\end{array}$ \\
\hline 1 & $\begin{array}{c}\text { Deleon }^{[14]} \\
\text { USA } \\
1993\end{array}$ & 5 & - & - & - & $\begin{array}{c}\text { Complete } \\
\text { Heart } \\
\text { Block }\end{array}$ & \\
\hline 2 & $\begin{array}{c}\text { Kabotu }^{[34]} \\
\text { Japan } \\
1996\end{array}$ & 11 & - & - & - & - & - \\
\hline 3 & $\begin{array}{c}\text { Kumar }^{[33]} \\
\text { India } \\
2002\end{array}$ & 12 & - & - & - & - & $0.6-2.7$ \\
\hline 4 & $\begin{array}{c}\text { Tawar }^{[36]} \\
\text { India } \\
2007\end{array}$ & 15 & - & - & - & - & - \\
\hline 5 & $\begin{array}{c}\text { Takahashi }^{[37]} \\
\text { Japan } \\
2008\end{array}$ & 14 & 7 & - & - & - & \\
\hline 6 & $\begin{array}{c}\text { Paulista }^{[38]} \\
\text { Brazil } \\
2009\end{array}$ & 95 & - & - & - & - & - \\
\hline \multirow[t]{2}{*}{7} & $\begin{array}{c}\text { Chowdhury }{ }^{[12} \\
\text { India } \\
2011\end{array}$ & 7 & & & & & $0.08-8.6$ \\
\hline & & 159 & $7(4.4 \%)$ & & & $1(0.6 \%)$ & \\
\hline
\end{tabular}

Table 5. The summary of all the surgical options.

\begin{tabular}{|c|c|c|c|c|c|c|}
\hline Procedure & $\begin{array}{l}\text { Number of } \\
\text { Patients }\end{array}$ & $\begin{array}{l}\text { SND } \\
(\%)\end{array}$ & $\begin{array}{l}\text { SVO } \\
(\%)\end{array}$ & $\begin{array}{c}\text { PVO } \\
(\%)\end{array}$ & $\begin{array}{c}\text { Others } \\
(\%)\end{array}$ & $\begin{array}{l}\text { Follow } \\
\text { up (yr) }\end{array}$ \\
\hline $\begin{array}{l}\text { Autogenous } \\
\text { right atrial } \\
\text { appendage }\end{array}$ & $159(17.0 \%)$ & $7(4.4 \%)$ & - & - & $1(0.6 \%)$ & $0.08-8.6$ \\
\hline $\begin{array}{l}\text { Single } \\
\text { patch } \\
\text { technique }\end{array}$ & $291(29.3 \%) 1$ & $15(5.2 \%)$ & $12(4.1 \%)$ & $10(3.6 \%)$ & 0 & $0.3-24$ \\
\hline $\begin{array}{l}\text { Double } \\
\text { patch }\end{array}$ & $185(19.8 \%) 1$ & $6(8.6 \%)$ & $4(2.2 \%)$ & $1(0.5 \%)$ & $1(0.5 \%)$ & $1.9-16$ \\
\hline $\begin{array}{l}\text { Warden's } \\
\text { procedure }\end{array}$ & $275(33.8 \%)$ & $5(1.9 \%)$ & $8(3.5 \%)$ & $5(1.6 \%)$ & $1(0.3 \%)$ & $0.08-30$ \\
\hline
\end{tabular}

and autologous right atrial appendage 5(1.8\%) in those who had Warden's procedure. Systemic venous obstruction occurred in $12(4.4 \%)$ of patients with single-patch technique, $8(2.9 \%)$ in those with Warden's procedure and in 4(2.2\%) of those who had double-patch technique and none in those who had autologous right atrial appendage. Pulmonary venous obstruction occurred in $10(3.6 \%)$ of those who had single-patch technique, $5(1.8 \%)$ of those who had Warden's procedure, $1(0.5 \%)$ of those who had double-patch technique. Other complications such as complete heart block was commonest in patients with autologous right atrial appendage $1(0.6 \%)$ followed by double-patch technique $1(0.5 \%)$ then Warden's procedure $1(0.4 \%)$ with none in patients with single-patch technique (Table 5).
Two studies $[13,16]$ compared the three surgical options of single-patch technique, double-patch technique and Warden's procedure. The combined result showed a total of 178 patients for which 84 patients had singlepatch technique, 49 patients had double-patch technique and 45 patients had Warden's procedure. Five patients (6\%) with single-patch technique had sinus node dysfunction, 12 patients $(24.5 \%)$ with double patch technique had sinus node dysfunction and no patients who had the Warden's procedure had sinus node dysfunction. Five patients $(2.3 \%)$ with single patch technique had systemic venous obstruction, 3 patients $(4.1 \%)$ with double-patch technique had systemic venous obstruction, 4 patients $(2.2 \%)$ with Warden's procedure had systemic venous obstruction. One patient (1.2\%) with single-patch technique had pulmonary venous obstruction, 1 patient $(2.0 \%)$ with double-patch technique had pulmonary venous obstruction and no patient with the Warden's procedure had pulmonary venous obstruction (Table 5).

\section{Discussion}

The first reported surgical treatment of SV-ASD was in 1950 by lobectomy as a result of bronchiectasis associated with the anomalous right pulmonary vein [3] and in 1953, there was another report of the repair using a closed technique [4]

With the evolving knowledge of the pathology, surgeons began to adopt surgical options that will suit the different pathological variants that may present, but unfortunately these again were characterized by some complications; chiefly amongst them were the sinus node dysfunction, systemic venous obstruction, pulmonary venous obstruction $[4,11-39,49]$.

The main goal of the repair of SV-ASD involves the closure of the septal defect and rechanneling of the anomalous pulmonary venous connection to the left atrium without attenuation of the superior vena caval or pulmonary venous flow and without the sino-atrial nodal dysfunction [10-12,25-31].

From the review, the surgical options can be classified into: 1) requiring incision or no incision across the cavoatrial junction [50], 2) the number of pericardial patch used (single or double patch) $[13,16], 3$ ) the way the right atrial is used (autologous right atrial free wall patch or autogenous atrial appendage) [12] and 4) the re-implantation of the right pulmonary veins $[11,39]$.

The allowance of continued drainage of an anomalous pulmonary vein in the right atrium or ligation of the vein and subsequent closure of the ASD as was done in some patients will convert a hitherto acyanotic problem to a cyanotic one by creating a complete transposition of the remaining right pulmonary veins if left pneumonectomy was done for such cases as trauma or tuberculosis, or even in left pneumonia Also, pulmonary venous collateral 
may form leading to systemic desaturation years following this surgical option [51-53].

One of the main complications that should be avoided in the repair of SV-ASD is venous obstruction; either systemic (involving mainly the superior vena cava) or pulmonary venous obstruction. In this review, the patients who had the single-patch technique experienced the highest incidence of venous obstruction as in this technique the caval or cavoatrial opening was not enlarged by the use of argumentation patch to ensure adequate venous drainage (Table 5).

In one study in which 3 patients developed postoperative systemic venous obstruction; 2 had single-patch technique, 1 had Warden's procedure and none had double-patch technique [16]. However, in another report, in which the double-patch technique was adopted, though quite a high number of the patients developed venous obstruction but it was merely described as mild, and thus considered as a mere turbulence that resulted from increased gradients across the different points. In spite of that, the conclusion was that the double-patch technique offered better results in terms of the prevention of venous obstruction [17].

In one account; 18 patients had double-patch technique with atriocavoplasty and the observation was that the enlarged SVC via the atrioplasty was effective in rerouting of the PAPVC without leading to venous obstruction [14]. In one reported case series with the highest number of patients who had double-patch with no evidence of the venous obstruction; the method involved extensive incision starting from the tip of right atrial appendage, upward along the atrial crest to the medial wall of the SVC. The ASD was closed by autologous pericardial patch and another pericardial patch was used to enclose the SVCright atrial junction to avoid narrowing of the SVC thus ensuring adequate venous drainage [22].

While the double-patch technique was helpful in enlarging the atriocaval or caval area to ensure unobstructed drainage of the SVC after the application of the second patch to baffle the right upper pulmonary vein drainage into the left atria; the adoption of a lateral approach was encouraged when using the single-patch technique, as, the modification, may offer wider opening of the SVC instead of making an anterior incision on the caval vein. That was the summation in one of the studies which also described single-patch as safe and simple technique that decreased systemic venous obstruction when the lateral transcaval incision was adopted [18]. Lateral incision was also used in another study with the highest number of 66 patients who had single-patch but with no venous obstruction complications $[15,42]$.

However, in another account, out of 30 patients who had the Warden's procedure, 4 developed venous obstruction; 3 was systemic vein obstruction and 1 was pulmonary vein obstruction and while stating that the procedure was equally a safe and an effective surgical option for the repair of PAPVC to the SVC but the resultant venous obstruction was common amongst the younger and smaller children as their vessels were commensurately small, and suggested that an argumentation patch should be considered if there was any suspicion that the anastomosis was not tension free as a result of technical error or this anatomical problems and also the use of absorbable sutures to allow for future growth $[10,28]$. Also, a technical error in anastomosis was given as a reason for the symptomatic superior vena cava obstruction in some patients who had Warden's procedure $[21,28]$.

In some anatomical variants such as SV-ASD with a high PAPVC; that is, the anomalous pulmonary vein is inserted more than $2 \mathrm{~cm}$ from the cavoatrial junction, the surgical repair with intra-atrial autologous pericardial patch has a high incidence of venous obstruction because of increased tendency for the patch to contract thereby resulting to symptomatic pulmonary vein obstruction. So, for this variant, the use of Warden's procedure was advocated as the effective surgical options [13,27]. Alternatively, a modified Warden's procedure which involved the anastomosis of the transected SVC to the amputated tip of the right atrial appendage with an anterior augmentation of pedicled autologous pericardial flap with the atrial septum directly displaced to the SVC opening. With this technique, the authors, observed that there was no patient with postoperative pulmonary vein obstruction; however, the 2 patients who had superior vena cava had left persisted superior vena cava (LSVC) [29]. Also, another authors observed that the incidence of stenosis or occlusion of the right SVC was more when it was associated with the presence of LSVC [38], but this was not the case with another study in which 58 patients were operated using the warden's procedure with $26(45 \%)$ patients having persistent LSVC but without any superior vena cava or pulmonary vein obstruction [10].

There are some technical details that ought to be applied in the anastomosis between the amputated tip of the right atrial appendage and the proximal SVC. The important points to be noted are; proper excision of the pectinate muscles to provide wide opening, ensuring tension free anastomosis and the use of absorbable sutures for the anastomosis to take care of future growth $[24,32]$. In this analysis, the use of Warden's procedure was the surgical option with the second commonest complications of venous obstruction; occurring in 13 patients (5.1\%).

The reason for the favourable surgical outcome when the right atrial appendage was used as conduit was because they were no calcifications or no thromboembolic problems or shrinkage of the patch which may have resulted from using of prosthetic or pericardial patch [37]. 
Contrary, another study in which the prosthetic or pericardial patches was used for the closure of ASD did not show any evidence of shrinkage as the histological analysis of explanted patch, for some other reason, revealed viable endothelium and subendothelial muscle on both surfaces of the patch [36].

Another mode of using of right atrial appendage in the surgical treatment of SV-ASD is that the right atrial appendage is anastomosed to the SVC (end to side) thereby providing a double outlet for the SVC. The advantage of the double outlet is that should the atriocaval anastomosis not be wide enough to drain the SVC, the native cavoatrial will augment the draining [12]. From the review (Table 5), the use of right atrial appendage as free wall flap or channeling conduit was attended with the least complication of postoperative venous obstruction and the use of double-patch technique and right atrial appendage offered the best protection against this complication [42].

Sinus Node Dysfunction (SND) will be reduced or rendered absent postoperatively when surgical maneuvers that clearly avoided incision across the cavoatrial junction were adopted. This is evident from the review as the incidence of SND was reduced when the right atrial appendage $(4.4 \%)$ or the Warden's procedure $(1.9 \%)$ were adopted as compared to double-patch technique (8.6\%) or single-patch technique (5.2\%).

From the largest reported case series, at the moment, of 58 patients who had repair of SV-ASD, none showed any evidence of SND postoperatively, and that was attributed to the adoption of the Wardens procedure which avoided incision across the cavoatrial junction [10]. Also, a retrospective analysis of 25 patients who had doublepatch technique, it was noted that the incidence of rhythm change from sinus to low atrial or junctional rhythm was significant in 12 out of the 22 patients with a percentage of $55 \%$ and that was due to the use of the double-patch technique which was associated with a significantly greater incidence of SND [16].

The review showed that the surgical option with the highest incidence of $8.6 \%$ of SND was the double-patch technique (Table 5). However, in one method of double-patch technique which avoided incision across the cavoatrial junction by using combined Transcaval and atriotomy, there was no evidence of SND [21].

In two studies that used Warden's procedure in 40 and 32 patients respectively reported incidence of one case of SND each[26,33]. One noted that 1 patient had sick sinus syndrome as a late complication but did not require pacemaker insertion while another study observed that account their patient experienced a transient rhythm disturbance but was subsequently free of SND after a median follow-up of 2 years. The resolution of the SND after sometime may be explained from the fact that the inflammation/edema around the cavoatrial junction whi- ch compromised the blood supply to SA node subsided with time. Also, in the meta-analysis on the use of Warden's procedure, the conclusion was in support of the notion that preservation of the sinus node and its blood supply through the adoption of Warden's procedure resulted in near-absence of SND postoperatively [41]. Another surgical option with reduced incidence of SND was the use of right atrial appendage. The only incidence of SND from the use of right atrial appendage was from the study that recorded 7 patients with SND from all the 7 studies (Table 4). This is the only study with very high SND as complication. In their method, the atrial flap technique, which required incision or suture crossing the crista terminalis was used [54,55], and the SA node and its blood supply are located around that area might have been actually affected by the incision and suturing around the area [54,55]. Apart from the aforementioned high incidence of SND in the study, the use of autogenous right atrium from other studies did not result in any incidence of SND (Table 4).

What accounted for the reduced incidence of SND when the cavoatrial junction was preserved is mainly the pattern of blood supply to the ASD node $[54,56]$. Considering this fact, the incidence of SND was highest in surgical options requiring double-patch technique from our review.

So, in the adoption of any surgical option, two structures readily come into mind; the location of SA node and its blood supply. While the location of the SA node can be predicted using the summit of the crest of the right atrial appendage and the sulcus terminalis as landmarks, on external examination of the heart; on the other hand the location of the artery supplying the node is less predictable, thus if surgical injury was to be prevented with certainty, then the entire cavoatrial junction should be avoided [54]. The sinus nodal artery which is the largest atrial coronary branch may originate from the right or left coronary artery and encircles the orifice of the SVC in either a clockwise or a counterclockwise direction [56]. Thus double-patch technique which requires the incision of the anterior portion of the SVC and also compromises the posterior applied blood supply because of a posterior suture line was associated with the highest incidence of SND. Thus both the anterior incision with subsequent patch and the posterior sutures in placing the intra-atrial pericardial baffle all compromise the blood supply to the SA node to a greater extent with the adoption of double-patch technique. While avoiding the cavoatrial junction which harbours the aborising blood supply to the Sinoatrial node [21] will all achieve the reduction of SND post operatively.

\section{Limitations of the Review}

Most of the studies failed to show clear follow-up of the 
patients and thus long term complications cannot be actively assessed.

\section{Conclusion}

The two major complications are SND and venous obstruction assume a see-saw approach as surgical maneuvers favoring the lack or decrease in venous obstruction encouraged the complication of SND; as what was gained by good venous drainage was lost to SND and vice versa.

\section{REFERENCES}

[1] J. R. Herlong, J. J. Jaggers and R. M. Ungerleider, "Congenital Heart Surgery Nomenclature and Database Project: Pulmonary Venous Anomalies," The Annals of Thoracic Surgery, Vol. 69, Suppl. 4, 2000, pp. S56-S69. http://dx.doi.org/10.1016/S0003-4975(99)01237-0

[2] N. A. Blom, A. C. Gittenberger-de Groot, T. H. Jongeneel, M. C. DeRuiter, R. E. Poelmann and J. Ottenkamp, "Normal Development of the Pulmonary Veins in Human Embryos and Formulation at a Morphogenetic Concept for Sinus Venosus Defects," American Journal of Cardiology, Vol. 87, No. 3, 2001, pp. 305-309. http://dx.doi.org/10.1016/S0002-9149(00)01363-1

[3] E. H. Drake and J. P. Lynch, "Bronchiectasis Associated with Anomaly of the Right Pulmonary Vein and Right Diaphragm," The Journal of Thoracic Surgery, Vol. 19, No. 3, 1950, pp. 433-437.

[4] W. B. Neptune, C. P. Bailey and H. Goldberg, "The Surgical Correction of Atrial Septal Defects Associated with Transposition of Pulmonary Veins," The Journal of Thoracic and Cardiovascular Surgery, Vol. 25, No. 6, 1953, p. 623.

[5] C. Chartrand, M. Payot, A. Davignon, R. Guerin, P. Stanley and J. Bruneau, "A New Surgical Approach for Correction of Partial Anomalous Pulmonary Venous Drainage into the Superior Vena Cava," The Journal of Thoracic and Cardiovascular Surgery, Vol. 71, No. 1, 1976, pp. 29-34.

[6] J. R. Hamilton, S. G. Brooks and D. R. Walker, "Alternative Technique for Repair of Sinus Venosus Atrial Septal Defect," The Annals of Thoracic Surgery, Vol. 51, No. 1, 1991, pp. 144-146.

http://dx.doi.org/10.1016/0003-4975(91)90475-6

[7] R. K. Woods and K. L. Cleveland, “Alternative Repair for Challenging Variants of Partial Anomalous Pulmonary Veins," The Annals of Thoracic Surgery, Vol. 85, No. 5, 2008, pp. 1823-1824.

http://dx.doi.org/10.1016/j.athoracsur.2007.12.029

[8] J. L. Russell, J. G. LeBlanc, L. M. Deagle and J. E. Potts, "Outcome Following Repairs of Sinus Venosus Atrial Septal Defects in Children," Asian Cardiovascular and Thoracic Annals, Vol. 10, No. 3, 2002, pp. 231-234. http://dx.doi.org/10.1177/021849230201000309

[9] E. R. Kyger, O. H. Frazier, D. A. Cooley, P. C. Gillette, G. J. Reul, F. M. Sandiford and D. C. Wukasch, "Sinus
Venosus Atrial Septal Defect: Early and Late Results Following Closure in 109 Patients," The Annals of Thoracic Surgery, Vol. 25, No. 1, 1978, pp. 44-50. http://dx.doi.org/10.1016/S0003-4975(10)63485-6

[10] V. Agarwal, K. E. Okonta, U. Abubakar and S. Gichuhi, "Impact of Warden's Procedure on the Sinus Rhythm: Our Experience," Heart, Lung and Circulation, Vol. 20, No. 11, 2011, pp. 718-721. http://dx.doi.org/10.1016/j.hlc.2011.08.004

[11] K. Abbasi, A. Abbasi, M. Tazik, A. Salehiomran, A. Kazemisaeed and H. Sadeghian, "Anomalous Right-Sided Pulmonary Venous Connection to the Superior Vena Cava," Monaldi Archives for Chest Disease, Vol. 72, No. 1, 2009, pp. 37-39.

[12] U. K. Chowdhury, S. M. Reddy, P. Gharde, V. Devagourou and K. Rao, "An Alternative Technique for Rechanneling of Sinus Venosus Atrial Septal Defect with Partial Anomalous Pulmonary Venous Connection Using Autogenous Right Atrial Appendage," World Journal for Pediatric and Congenital Heart Surgery, Vol. 2, No. 2, 2011, pp. 231-236.

[13] S. Stewart, C. Alexson and J. Manning, "Early and Late Results of Repair of Partial Anomalous Pulmonary Venous Connection to the Superior Vena Cava with a Pericardial Baffle," The Annals of Thoracic Surgery, Vol. 41, No. 5, 1986, pp. 498-501. http://dx.doi.org/10.1016/S0003-4975(10)63026-3

[14] S. Y. DeLeon, J. E. Freeman, M. N. Ilbawi, T. S. Husayni, J. A. Quinones, E. P. Ow, et al., "Surgical Techniques in Partial Anomalous Pulmonary Veins to the Superior Vena Cava," The Annals of Thoracic Surgery, Vol. 55, No. 5, 1993, pp. 1222-1226. http://dx.doi.org/10.1016/0003-4975(93)90038-J

[15] I. A. Nicholson, R. B. Chard, G. R. Nunn and T. B. Cartmill, "Transcaval Repair of Sinus Venosus Syndrome," The Journal of Thoracic and Cardiovascular Surgery, Vol. 119, No. 4, 2000, pp. 741-744.

[16] R. D. Stewart, F. Bailliard, A. M. Kelle, C. L. Backer, L. Young and C. Mavroudis, "Evolving Surgical Strategy for Sinus Venous Atrial Septal Defect: Effect on Sinus Node Function and Late Venous Obstruction," The Annals of Thoracic Surgery, Vol. 84, No. 5, 2007, pp. 16511655. http://dx.doi.org/10.1016/j.athoracsur.2007.04.130

[17] A. P. Iyer, K. Somanrema, S. Pathak, P. Y. Manjunath, S. Pradhan and S. Krishnan, "Comparative Study of Singleand Double-Patch Techniques for Sinus Venosus Atrial Septal Defect with Partial Anomalous Pulmonary Venous Connection," The Journal of Thoracic and Cardiovascular Surgery, Vol. 133, No. 3, 2007, pp. 656-659. http://dx.doi.org/10.1016/i.jtcvs.2006.08.076

[18] T. P. Gajjar, C. S. Hiremath and N. B. Desai, "Surgical Closure of Sinus Venosus Atrial Septal Defect Using a Single-Patch Transcaval Repair Technique," Journal of Cardiac Surgery, Vol. 26, No. 4, 2011, pp. 429-434. http://dx.doi.org/10.1111/j.1540-8191.2011.01270.x

[19] S. M. Said, H. M. Burkhart, H. V. Schaff, F. Cetta Jr., S. D. Philips, R. D. Barnes, et al., "Single-Patch, 2-Patch, and Caval Division Techniques for Repair of Partial Anomalous Pulmonary Venous Connections: Does It 
Matter? The Journal of Thoracic and Cardiovascular Surgery, Vol. 143, No. 4, 2012, pp. 896-903. http://dx.doi.org/10.1016/j.jtcvs.2011.09.074

[20] M. Nassar, V. Fouilloux, L. Mace, B. Kreitmann and D. Metras, "Transcaval Correction of Partial Anomalous Pulmonary Venous Drainage into the Superior Vena Cava," The Annals of Thoracic Surgery, Vol. 93, No. 1, 2012, pp. 193-196. http://dx.doi.org/10.1016/j.athoracsur.2011.09.042

[21] S. Victor and V. M. Nayak, "Transcaval Repair of Sinus Venosus Defect. Using a Butterfly-Shaped Patch," Texas Heart Institute Journal, Vol. 22, No. 4, 1995, pp. 304307.

[22] S. K. Agrawal, S. K. Khana and D. Tampe, "Sinus Venosus Atrial Septal Defects: Surgical Follow-Up," European Journal Cardio-Thoracic Surgery, Vol. 11, No. 3, 1997, pp. $455-457$. http://dx.doi.org/10.1016/S1010-7940(96)01082-2

[23] M. Jemielity, B. Perek, L. Paluszkiewicz, W. Stachowiak and A. Ponizynki, "Results of Repair of Partial Anomalous Pulmonary Venous Connection and Sinus Venosus Atrial Septal Defect in Adults," The Journal of Heart Valve Disease, Vol. 7, No. 4, 1998, pp. 410-414.

[24] H. E. Warden, R. A. Gustafson, T. J. Tarnay and W. A. Neal, "An Alternative Method for Repair of Partial Anomalous Pulmonary Venous Connection to the Superior Vena Cava," The Annals of Thoracic Surgery, Vol. 38, No. 6, 1984, pp. 601-605. http://dx.doi.org/10.1016/S0003-4975(10)62317-X

[25] R. A. Gustafson, H. E. Warden, G. F. Murray, R. C. Hill and G. E. Rozar, "Partial Anomalous Pulmonary Venous Connection to the Right Side of the Heart," The Journal of Thoracic and Cardiovascular Surgery, Vol. 98, No. 5, 1989, pp. 861-868.

[26] R. A. Gustafson, H. E. Warden and G. F. Murray, "Partial Anomalous Pulmonary Venous Connection to the Superior Vena Cava," The Annals of Thoracic Surgery, Vol. 60, Suppl. 3, 1995, pp. 614-617. http://dx.doi.org/10.1016/0003-4975(95)00854-3

[27] J. W. Gaynor, M. Burch, C. Dollery, I. D. Sullivan, J. E. Deanfield and M. J. Elliott, "Repair of Anomalous Pulmonary Venous Connection to the Superior Vena Cava," The Annals of Thoracic Surgery, Vol. 59, No. 6, 1995, pp. 1471-1475. http://dx.doi.org/10.1016/0003-4975(95)00150-J

[28] D. J. DiBardino, E. D. McKenzie, J. S. Heinle, J. T. Su and C. D. Fraser Jr., "The Warden Procedure for Partially Anomalous Pulmonary Venous Connection," Cardiology in the Young, Vol. 14, No. 1, 2004, pp. 64-67.

[29] A. Nakahira, T. Yagihara, K. Kagisaki, I. Hagino, T. Ishizaka, M. Koh, et al., "Partial Anomalous Pulmonary Venous Connection to the Superior Vena Cava," The Annals of Thoracic Surgery, Vol. 82, No. 3, 2006, pp. 978-982. http://dx.doi.org/10.1016/j.athoracsur.2006.02.013

[30] A. Shahriari, M. D. Rodefeld, M. W. Turrentine and J. W. Brown, "Caval Division Technique for Sinus Venosus Atrial Septal Defect with Partial Anomalous Pulmonary Venous Connection," The Annals of Thoracic Surgery, Vol. 81, No. 1, 2006, pp. 224-229. http://dx.doi.org/10.1016/j.athoracsur.2005.07.015

[31] C. S. Park, J. G. Kwak, C. Lee, C. H. Lee, S. Y. Lee, E. Y. Choi, et al., "Partial Anomalous Pulmonary Venous Connection to the Superior Vena Cava: The Outcome after the Warden Procedure," European Journal Cardio-Thoracic Surgery, Vol. 41, No. 2, 2012, pp. 261-265.

http://dx.doi.org/10.1016/j.ejcts.2011.05.043

[32] B. P. Kottayil, B. S. Dharan, S. Menon, S. Bijulal, P. K. Neema, S. K. Gopalakrishnan, et al., "Anomalous Pulmonary Venous Connection to Superior Vena Cava: Warden Technique," European Journal Cardio-Thoracic Surgery, Vol. 39, No. 3, 2011, pp. 388-391. http://dx.doi.org/10.1016/j.ejcts.2010.06.036

[33] S. M. Said, H. M. Burkhart, J. A. Dearani, B. Eidem, P. Stensrud, S. D. Phillips, et al., "Outcome of Caval Division Techniques for Partial Anomalous Pulmonary Venous Connections to the Superior Vena Cava," The Annals of Thoracic Surgery, Vol. 92, No. 3, 2011, pp. 980984. http://dx.doi.org/10.1016/j.athoracsur.2011.04.110

[34] H. Kubota, A. Furuse, Y. Kotsuka, K. Yagyu, K. Hirata and Y. Murakawa, "Midterm Results of the RotationAdvancement Flap Method for Correction of Partial Anomalous Pulmonary Venous Drainage into the Superior Vena Cava," The Journal of Thoracic and Cardiovascular Surgery, Vol. 112, No. 1, 1996, pp. 1-7. http://dx.doi.org/10.1016/S0022-5223(96)70170-8

[35] A. S. Kumar, S. K. Choudhary, R. Ray, S. Talwar and R. Juneja, "Autologous Right Atrial Patch for Closure of Atrial Septal Defect," Indian Heart Journal, Vol. 54, No. 3, 2002, pp. 289-291.

[36] S. Talwar, S. K. Choudhary, A. Mathur and A. S. Kumar, "Autologous Right Atrial Wall Patch for Closure of Atrial Septal Defect," The Annals of Thoracic Surgery, Vol. 84, No. 3, 2007, pp. 913-916. http://dx.doi.org/10.1016/j.athoracsur.2007.04.067

[37] H. Takahashi, Y. Oshima, M. Yoshida, M. Yamaguchi, K. Okada and Y. Okita, "Sinus Node Dysfunction after Repair of Partial Anomalous Pulmonary Venous Connection," The Journal of Thoracic and Cardiovascular Surgery, Vol. 136, No. 2, 2008, pp. 329-334. http://dx.doi.org/10.1016/j.jtcvs.2007.12.039

[38] M. D. Paulista, P. H. Paulista, A. L. Guerra and P. P. Paulista, "Surgical Treatment of Partial Anomalous Pulmonary Venous Connection to the Superior Vena Cava," Revista Brasileira de Cirurgia Cardiovascular, Vol. 24, No. 2, 2009, pp. 133-137.

[39] B. Alsoufi, S. Cai, G. S. Van Arsdell, W. G. Williams, C. A. Caldarone and J. G. Coles, "Outcomes after Surgical Treatment of Children with Partial Anomalous Pulmonary Venous Connection," The Annals of Thoracic Surgery, Vol. 84, No. 6, 2007, pp. 2020-2026. http://dx.doi.org/10.1016/j.athoracsur.2007.05.046

[40] J. I. Aramendi, E. Rey, G. Hamzeh, A. Crespo, M. Luis and R. Voces, "Partial Anomalous Pulmonary Venous Connection to the Superior Vena Cava," The Annals of Thoracic Surgery, Vol. 91, No. 4, 2011, pp. 64-66. http://dx.doi.org/10.1016/j.athoracsur.2010.12.007

[41] K. E. Okonta and V. Agarwal, "Does Warden's Procedure Reduce Sinus Node Dysfunction after Surgery for Partial 
Anomalous Pulmonary Venous Connection?" Interactive CardioVasc Thoracic Surgery, Vol. 14, No. 6, 2012, pp. 839-842. http://dx.doi.org/10.1093/icvts/ivs038

[42] K. E. Okonta and M. Tamatey, "Is Double or Single Patch for Sinus Venosus Atrial Septal Defect Repair the Better Option in Prevention of Postoperative Venous Obstruction?" Interactive CardioVasc Thoracic Surgery, Vol. 15, No. 5, 2012, pp. 900-903. http://dx.doi.org/10.1093/icvts/ivs369

[43] R. E. Walker, J. E. Mayer, M. E. Alexander, E. P. Walsh and C. I. Berul, "Paucity of Sinus Node Dysfunction Following Repair of Sinus Venosus Defects in Children," American Journal of Cardiology, Vol. 87, No. 10, 2001, pp. 1223-1226.

http://dx.doi.org/10.1016/S0002-9149(01)01504-1

[44] L. K. Groves, "Correction of Anomalous Pulmonary Venous Drainage into the Superior Vena Cava," The Annals of Thoracic Surgery, Vol. 4, No. 4, 1967, pp. 301-307. http://dx.doi.org/10.1016/S0003-4975(10)66518-6

[45] G. A. Trusler, G. Kazenelson, R. M. Freedom, W. G. Williams and R. D. Rowe, "Late Results Following Repair of Partial Anomalous Pulmonary Venous Connection with Sinus Venosus Atrial Septal Defect," The Journal of Thoracic and Cardiovascular Surgery, Vol. 79, No. 5, 1980, pp. 776-781.

[46] M. Ohmi and H. Mohri, "A Single Pericardial Patch Technique for Repair of Partial Anomalous Pulmonary Venous Drainage Associated with Sinus Venosus Atrial Septal Defect," The Annals of Thoracic Surgery, Vol. 46, No. 3, 1988, pp. 360-361.

http://dx.doi.org/10.1016/S0003-4975(10)65949-8

[47] G. B. Luciani, F. Viscardi, M. Pilati, R. Crepaz, G. Faggian and A. Mazzucco, "Age at Repair Affects the Very Long-Term Outcome of Sinus Venosus Defect," The Annals of Thoracic Surgery, Vol. 86, No. 1, 2008, pp. 153159. http://dx.doi.org/10.1016/j.athoracsur.2008.03.045

[48] A. N. Lewin, C. Zavanella and S. Subramanian, "Sinus Venosus Atrial Septal Defect Associated with Partial Anomalous Pulmonary Venous Drainage: Surgical Repair," The Annals of Thoracic Surgery, Vol. 26, No. 2,
1978 , pp. $185-188$. http://dx.doi.org/10.1016/S0003-4975(10)63662-4

[49] M. T. M. Mommersteeg, J. N. Domınguez, C. Wiese, J. Norden, C. G. Vries and J. B. E. Burch, et al., "The Sinus Venosus Progenitors Separate and Diversify from the First and Second Heart Fields Early in Development," Cardiovascular Research, Vol. 87, No. 1, 2010, pp. 92101. http://dx.doi.org/10.1093/cvr/cvq033

[50] S. Buz, V. Alexi-Meskishvili, F. Villavicencio-Lorini, M. Yigitbasi, M. Hubler, Y. Weng, et al., "Analysis of Arrhythmias after Correction of Partial Anomalous Pulmonary Venous Connection," The Annals of Thoracic Surgery, Vol. 87, No. 2, 2009, pp. 580-583. http://dx.doi.org/10.1016/j.athoracsur.2008.11.018

[51] P. Zubiate and J. H. Kay, "Surgical Correction of Anomalous Pulmonary Venous Connection," Annals of Surgery, Vol. 151, No. 2, 1962, pp. 234-250.

[52] H. S. Weber, R. I. Markowitz, W. E. Hellenbrand, C. S. Kleinman and G. S. Kopf, "Pulmonary Venous Collaterals Secondary to Superior Vena Cava Stenosis: A Rare Cause of Right-to-Left Shunting Following Repair of a Sinus Venosus Atrial Septal Defect," Pediatric Cardiology, Vol. 10, No. 1, 1989, pp. 49-51. http://dx.doi.org/10.1007/BF02328636

[53] K. E. Okonta, "The Challenges of Surgical Management of Lung Pathology with Anomalous Pulmonary Vein," Interactive CardioVasc Thoracic Surgery, Vol. 15, No. 2, 2012, p. 327. http://dx.doi.org/10.1093/icvts/ivs250

[54] K. R. Anderson, S. Y. Ho and R. H. Anderson, "Location and Vascular Supply of Sinus Node in Human Heart," British Heart Journal, Vol. 41, No. 1, 1979, pp. 28-32. http://dx.doi.org/10.1136/hrt.41.1.28

[55] T. N. James, "Anatomy of the Human Sinus Node," The Anatomical Record, Vol. 141, No. 2, 1961, pp. 109-116. http://dx.doi.org/10.1002/ar.1091410205

[56] L. Verhaeghe and L. Van Der Hauwaert, "Arterial Blood Supply of the Human Sinus Node," British Heart Journal, Vol. 29, 1967, pp. 801-806. http://dx.doi.org/10.1136/hrt.29.5.801 